\title{
POKOK-POKOK PERDEBATAN YESUS DENGAN PARA PEMIMPIN YAHUDI DALAM YOHANES 5: 19-47
}

\author{
Oleh : \\ ${ }^{* 1}$ Mathias Jebaru Adon, ${ }^{* 2}$ Stanislaus Eko Riyadi \\ ${ }^{*}$ Sekolah Tinggi Filsafat Teologi Widya Sasana Malang, \\ ${ }^{*}$ Fakultas Teologi, Universitas Sanata Dharma Yogyakarta \\ Email: ${ }^{* 1}$ mathiasjebaruadon@gmail.com, ${ }^{* 2}$ ekoriyadi@gmail.com
}

\begin{abstract}
ABSTRAK: Tulisan ini bertujuan mengungkapkan pokok-pokok perdebatan Yesus dengan pemimpin-pemimpin Yahudi dalam Injil Yohanes bab 5: 19-47. Pernyataan-pernyataan yang disampaikan Yesus dalam perdebatan tersebut dianggap oleh pemimpin-pemimpin bangsa Yahudi sebagai penghujatan kepada Allah dan Taurat. Atas dasar ini, para pemimpin Yahudi bersepakat untuk membunuh Yesus. Karena itu, perikop Injil Yohanes 5:19-47 menjadi salah satu bagian penting untuk mengerti keseluruhan konflik dalam Injil Yohanes. Dalam Injil Yohanes segala sesuatu yang dikatakan dan dilakukan Yesus ditolak dan ditentang oleh pemimpin-pemimpin Yahudi. Penginjil Yohanes menempatkan kelompok ini sebagai penentang Yesus yang sejak awal sampai akhir tidak mengubah sikapnya. Dalam konteks jemaat semacam inilah, Yohanes menulis injil agar semua orang menjadi percaya dan diselamatkan. Penelitian ini menggunakan studi kepustakaan atas sumber-sumber dan interpretasi Injil Yohanes. Melalui penelitian ini diharapkan para pembaca Injil Yohanes memahami tujuan teologis di balik Injil Yohanes. Sebab secara literer Injil Yohanes memiliki perbedaan yang cukup signifikan dengan injil-injil sinoptik.
\end{abstract}

Kata kunci: Injil Yohanes, Kaum Farisi, Hari Sabat dan Sabda Yesus.

ABSTRACT: This paper aims to reveal the points of Jesus' debate with the Jewish leaders in the Gospel of John chapter 5:19-47. The statements made by Jesus in the debate were considered by the Jewish leaders as blasphemy against God and the Torah. On this basis, the Jewish leaders agreed to kill Jesus. Therefore, the passage of the Gospel of John 5:19-47 becomes an important part to understand the whole conflict in the Gospel of John. In the Gospel of John, everything Jesus said and did was rejected and opposed by the Jewish leaders. Evangelist John puts this group as opponents of Jesus who from the beginning to the end did not change his attitude. In the context of this kind of church, John wrote the gospel so that all people might believe and be saved. This study uses a literature study of the sources and interpretations of the Gospel of John. Through this research, it is hoped that the readers of the Gospel of John will understand the theological purpose behind the 
Gospel of John. Because literally, the Gospel of John has a significant difference from the synoptic gospels.

Keywords: Gospel of John, Pharisees, Sabbath and the Word of Jesus

\section{PENDAHULUAN}

Injil Yohanes merupakan Injil yang memiliki perbedaan yang cukup signifikan dibandingkan dengan Injil-injil Sinoptik, baik dari segi literer maupun kronologi peristiwa. Bahasa yang digunakan sangat agung dan berwibawa. Dalam Injil Yohanes kata kerja seperti kotbah, mengajar sering sekali ditemukan. Oleh karena itu sebagian besar Injil Yohanes berisi pengajaran, dan kurang banyak menampilkan cerita mujizat dan kisah. Tidak heran jika Yesus ditampilkan dalam Injil Yohanes sebagai guru agung yang mengajar segala sesuatu dengan penuh wibawa dan otoritas. ${ }^{1}$

Dalam keseluruhan injilnya, Yohanes hanya menampilkan 7 kisah mujizat, dan kata yang dipakai bukan mujizat tetapi tanda. Gaya penulisan injilnya, Yohanes tidak hanya menampilkan fakta tetapi mengandung amanat rohani yang dalam. Misalnya tanda Yesus mengubah air menjadi anggur menggambarkan Perjanjian Lama yang diubah menjadi Perjanjian Baru. ${ }^{2}$ Dari segi kronologi peristiwa kisah Injil Yohanes memiliki perbedaan dengan Injil Sinoptik. Dalam Injil Sinoptik kisah Yesus Membersihkan Bait Allah diceritakan di akhir pelayanan Yesus (Mat. 21: 12-13, Mrk. 11:15-17, Luk. 19:45-46) sedangkan

\footnotetext{
${ }^{1}$ Christian Jonch, "Yesus Sebagai Guru : Studi Injil Yohanes," Veritas : Jurnal Teologi dan Pelayanan 8, no. 2 (2007): 257-276.

${ }^{2}$ Rainer Scheunemann, Panduan Lengkap Penafsiran Alkitab: Perjanjian Lama Dan
}

dalam Injil Yohanes kisah ini ditempatkan pada bagian awal (Yoh. 2: 13-25).

Hal ini menunjukkan bahwa Injil Yohanes memiliki kekhasan dibandingkan injil-injil lain. Dalam injilnya Yohanes banyak menampilkan simbol seperti air, cahaya, roti dan lain-lain yang tidak dimaknai begitu saja tetapi memiliki makna teologis yang mendalam. ${ }^{3}$ Gambaran ini nampak ketika Yesus memperbaiki ketidakpahaman Nikodemus tentang "lahir kembali”. Pernyataan dilahirkan kembali bukan berarti dilahirkan untuk kedua kalinya secara fisik tetapi dilahirkan kembali oleh Roh (Yohanes 3:3-8). Demikian halnya dengan kisah percakapan dengan Perempuan Samaria di pinggir Sumur Yakub bahwa "air" yang Ia tawarkan bukanlah air dari sumur melainkan hidup yang kekal (Yohanes 4:10-14). Dengan kata lain Injil Yohanes ingin mempertegas Yesus sebagai Mesias. Tujuan ini dinyatakan secara eksplisit oleh Yohanes dalam 20:31, yakni supaya semua orang percaya bahwa Yesus adalah Mesias, Anak Allah, dan oleh karena iman memperoleh hidup dalam nama-Nya.

Itulah sebabnya penginjil Yohanes mendedikasikan bab pertama injilnya untuk menunjukkan identitas Yesus, yang diramu dalam bentuk interogasi Yohanes Pembaptis oleh pemimpin bangsa Yahudi

Perjanjian Baru (Yogyakarta: ANDI Offset Yogyakarta, 2009).

${ }^{3}$ Petrus Lakonawa, "Memaknai Simbol-Simbol Religius Injil Yohanes," Humaniora 5, no. 1 (2014): 324. 
(Yoh. 1:19). Namun Yohanes Pembaptis dengan tegas mengatakan bahwa dirinya bukan Mesias, bukan Elia dan juga bukan Nabi yang akan datang sebab ia sadar bahwa Yesuslah Mesias, Elia dan Musa yang baru.

Kesaksian Yohanes Pembaptis tentang Yesus sebagai Mesias, Nabi dan Elia pada awalnya tidak menimbulkan persoalan bagi orang-orang Farisi dan pemimpin-pemimpin bangsa Yahudi. Bab 1 sampai Bab 4 tidak ditemukan kesulitan besar untuk menerima Sabda dan Mujizat Yesus. Semuanya berjalan lancar tanpa pertentangan. Konflik mulai muncul ketika semakin banyak orang menaruh kepercayaan kepada Yesus. Sejak saat itu apa saja yang dilakukan Yesus: Sabda dan mujizat-Nya menimbulkan penolakan dan pertentangan.

Perdebatan itu dimulai dalam Yoh. 5:19-46 setelah Yesus menyembuhkan orang sakit di Kolam Betesda. Pada sat itu, Yesus menerangkan siapa diri-Nya; kuasa dan otoritas perbuatan dan pengajaran-Nya. Sejak saat itu, penjelasan tentang identitas Yesus mewarnai keseluruhan penulisan Injil Yohanes yang diracik dalam pelbagai kisah dan pengajaran. Karena itu untuk memahami keseluruhan Injil Yohanes dan motif teologis penulisannya, baiklah untuk mengerti pokok-pokok perdebatan Yesus dengan pemimpin Yahudi yang terdapat dalam Yoh. 5: 19-47. Pokok-pokok perdebatan itu antara lain menyangkut otoritas dan kuasa Yesus, asal-usul

\footnotetext{
${ }^{4}$ Epelina Yofita Runesi, "Kritik Yesus Terhadap Orang Farisi Berdasarkan Matius 23:1-12 (Sebuah Studi Eksegesis)," Repository Sekolah Tinggi Teologi Injili Arastamar (SETIA) Jakarta 12 (2015).
}

pengajaran dan pekerjaannya, penghakiman dan kesaksian Yesus tentang diri-Nya.

Penelitian tentang perdebatan Yesus dengan orang-orang Farisi telah banyak dilakukan. Misalnya kritik Yesus terhadap orang Farisi dalam Mat. 23: 1-12. Penelitian ini dijalankan oleh Epelina Yofita Runesi (2015). Dalam penelitian tersebut Runesi melihat bahwa konflik antara Yesus dan orang Farisi sering terjadi karena praktik hidup dan keagamaan orang Farisi cenderung legalistik, munafik dan mementingkan diri sendiri. Menurut Runesi hal ini terjadi karena orang Farisi cenderung menafsir Taurat secara harafiah. ${ }^{4}$ Selain itu penafsiran yang salah mengenai Kerajaan Allah turut mempengaruhi sikap dan pemahaman mereka.

Orang Farisi mengerti Kerajaan Allah sebagai Allah yang datang sebagai Hakim yang mengadili dunia; menghukum yang berdosa dan menyelamatkan yang setia (Yesaya 4; 2-4; Yehezkiel 20: 34-38). Pemahaman yang keliru inilah yang menyebabkan orang Yahudi mentaati Taurat secara sempurna. Penelitian ini dilakukan oleh Nur Budi Santosa (2013). Konsekuensinya orang Farisi Yesus menganggap Yesus sebagai penentang Taurat. Karena itu mereka memposisikan diri sebagai tokoh yang berseberangan dengan Yesus. ${ }^{5}$

Maka dalam penelitian yang dilakukan oleh Finki Rianto Kantohe (2020) menyebut orang Farisi sebagai kelompok narsis dalam kehidupan beragama. ${ }^{6}$ Tetapi gagasan ini hanya dapat

\footnotetext{
${ }^{5}$ Nur Budi Santosa, "Konsep Kerajaan Allah Menurut Yesus,” Jurnal Antusias (2013).

${ }^{6}$ Finki Rianto Kantohe, "Orang-Orang Farisi Dan Narsisisme Beragama: Tinjauan Mengenai Potret Orang-Orang Farisi Dalam Yohanes 9," Jurnal Abdiel: Khazanah Pemikiran Teologi,
} 
dimengerti bila melakukan kajian yang mendalam tentang konteks sosio-historis Injil Yohanes. Oleh sebab itu kebaruan penelitian ini terletak pada uraian mengenai konteks historis jemaat Yohanian sehingga dapat memahami latar belakang yang menjadi pokok-pokok perdebatan Yesus dengan pemimpin-pemimpin Yahudi.

Namun, Yohanes melaporkan bahwa tidak semua orang Yahudi menentang Yesus. Injil Yohanes melaporkan terdapat pemimpin Yahudi yang diam-diam percaya kepada Yesus seperti Nikodemus (Yoh. 3: 1-21). Di samping itu tidak semua orang Yahudi yang menolak Yesus. Kisah penyembuhan orang buta sejak lahir dalam Yohanes 9 mengindikasikan bahwa orang tua si buta berada dalam ketakutan dan tekanan karena takut dikucilkan dari Sinagoga jika mengakui Yesus sebagai Mesias.

Kisah-kisah ini menggambarkan bahwa hanya kelompok eksklusif Yahudi saja yang sejak awal menolak Yesus, dan sikap ini terus dibawa sampai akhirnya Yesus disalibkan. Dengan kata lain, pokokpokok perdebatan Yesus dengan kelompokkelompok eksklusif Yahudi inilah yang mewarnai karakter penulisan Injil Yohanes.

\section{METODE PENELITIAN}

Penelitian ini adalah sebuah penelitian kualitatif melalui studi kepustakaan atas sumber-sumber yang berisi pokok-pokok perdebatan Yesus dengan para pemimpin Yahudi dalam Injil Yohanes 5: 19-47. Sumber-sumber ini diteliti dan dikaji secara mendalam

Pendidikan Agama Kristen dan Musik Gereja 4, no. 2 (2020): 180-198.

${ }^{7}$ Yanjumseby Y. Manafe, "STTE Konsep Kesatuan Yesus Dan Allah Bapa Dalam Injil Yohanes 17 : sehingga ditemukan tema-tema yang mendukung penelitian. Sumber penelitian dibagi menjadi dua bagian yakni sumber data primer dan sumber data sekunder. Sumber data primer diperoleh dari Kitab Suci dan jurnal-jurnal ilmiah yang berisi interpretasi dan studi-studi atas Injil Yohanes. Sumber data sekunder diperoleh dari buku-buku yang berisi komentar tentang Injil Yohanes serta jurnal-jurnal ilmiah.

Kedua sumber ini dipadu secara harmonis sehingga ditemukan pokok-pokok perdebatan Yesus dengan para pemimpin Yahudi dalam Injil Yohanes 5: 19-47. Melalui metode ini dapat ditemukan persoalan teologis tujuan penulisan Injil Yohanes. Dengan cara ini semakin banyak dapat mengerti setiap pengajaran dan kisah yang disajikan dalam Injil Yohanes.

\section{HASIL DAN PEMBAHASAN Konteks Jemaat Injil Yohanes}

Sebagian besar penafsir sepakat bahwa Injil Yohanes ditulis pada abad pertama atau sekitar tahun $90 \mathrm{M}$ atau sebelum tahun 110 M. Kisah Yoh. 9: 22 menunjukkan data historis bahwa pada tahun $85 \mathrm{M}$ para pemimpin bangsa Yahudi memasukan kutukan bagi mereka yang meninggalkan agama Yahudi. Menurut tradisi Gereja, Yohanes wafat setelah ia menulis injilnya yakni 30 tahun setelah kematian Yesus. $^{7}$

Yoh. 19:35 menunjukkan bahwa pengarang Injil Yohanes adalah seorang saksi mata yakni murid yang dikasihi. Dalam Injil selalu dikatakan Petrus bersama

22 Untuk Menghadapi Doktrin Subordinansi Tritunggal Saksi Yehuwa," Jurnal Scripta Teologi dan Pelayanan Kontekstual 4, no. 1 (2019): 1-14. 
murid yang dikasihi. Murid yang selalu berjalan dengan Petrus yakni Yakobus dan Yohanes anak Zabedeus sehingga dapat dipastikan bahwa Yohanes anak Zabedeus adalah pengarang Injil Yohanes. Di samping itu, kebenaran bahwa Injil Yohanes ditulis setelah bait Allah di Yerusalem dihancurkan yakni tahun $70 \mathrm{M}$ membenarkan teori tersebut sebab Yohanes masih muda ketika Yesus disalibkan.

Dari sini dapat dipahami bahwa saat Injil Yohanes ditulis umat kristiani awali sedang berada dalam pergumulan iman yang berat yakni konflik antara orang-orang yang percaya dengan orang-orang Yahudi yang berpegang teguh dengan tradisi Yahudi. Sebab setelah kehancuran Bait Allah, orang-orang Yahudi kehilangan simbol identitasnya sebagai bangsa terpilih. Selain itu, kehancuran Bait Allah dianggap sebagai bukti ketidaksetiaan Israel terhadap Yahwe. Kristianitas dianggap sebagai sekte agama Yahudi dan dalang kehancuran Bait Allah. ${ }^{8}$

Dalam Injil Yohanes konflik ini sampai menyebabkan orang yang percaya terpinggirkan dari Sinagoge sedangkan dalam injil-injil sinoptik perdebatan dengan orang-orang Farisi hanya terjadi dalam lingkup sinagoge (Yoh. 9:22). ${ }^{9}$ Hal ini menunjukkan bahwa frekuensi konflik dalam Injil Yohanes jauh lebih besar ketimbang dalam Injil sinoptik. Meski demikian konflik tersebut tidak terjadi dengan semua bangsa Yahudi. Terdapat beberapa orang dari pemimpin Yahudi yang diam-diam percaya dan mengakui Yesus

\footnotetext{
${ }^{8}$ Hendrikus Berkhof, Sejarah Gereja, ed. H. Enklaar, 24th ed. (Jakarta: BPK Gunung Mulia, 2009).

${ }^{9}$ Kantohe, "Orang-Orang Farisi Dan Narsisisme Beragama: Tinjauan Mengenai Potret OrangOrang Farisi Dalam Yohanes 9."
}

sebagai Mesias yang akan datang. Yohanes pasal 3 mengisahkan Nikodemus seorang pengajar Israel malam-malam datang bercakap-cakap dengan Yesus. Plot waktu kedatangan Nikodemus pada malam hari menggambarkan situasi genting umat Kristiani yang berada dalam pengejaran.

Karena itu, untuk memahami pokok perdebatan Yesus dengan pemimpin Yahudi dalam Yoh. 5: 19-17, baiklah untuk sekilas melihat profil kelompok eksklusif Yahudi yang sejak awal sampai akhir menolak Yesus. Dari sini akan dimengerti pokok-pokok penolakan Yesus oleh pemimpin Yahudi.

\section{Kelompok-Kelompok Penentang Yesus Dalam Injil Yohanes}

Ciri khas Injil Yohanes yang sangat mencolok yakni konflik antara orang-orang yang menerima Yesus dengan para pemimpin eksklusif Yahudi yang tidak percaya. Maka pertanyaannya, siapakah orang Yahudi yang percaya kepada Yesus dan siapa yang menentang Yesus. Dalam

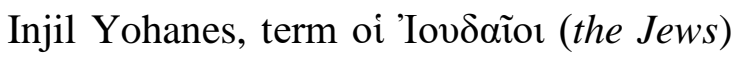
memiliki berbagai macam pemaknaan. ${ }^{10}$

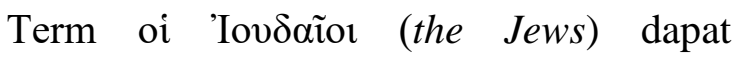
dikategorikan (1) Orang-orang Yahudi pada umumnya seperti orang-orang yang melayat Maria dan Martha ketika Lazarus meninggal (Yoh. 11). (2) Imam-imam kepala di Yerusalem, (3) Yahudi pengamat Taurat yakni kaum Farisi dan ahli Taurat, (4) Orang-orang Yahudi Yang percaya kepada Yesus, seperti orang tua si buta sejak lahir (Yoh. 9), dan (5) Kelompok-

\footnotetext{
${ }^{10}$ Hendrik Yufengkri Sanda, "Penderitaan, Dosa, Dan Pekerjaan-Pekerjaan Allah: Eksegesis Injil Yohanes 9:2-4," KAMASEAN: Jurnal Teologi Kristen 1, no. 1 (2020): 35-54.
} 
kelompok pewaris tradisi Yahudi tertentu yang secara terbuka menentang Yesus. ${ }^{11}$

Kelompok orang Yahudi yang sering digambarkan Yohanes merujuk kelompok 2, 3 dan 5. Mereka adalah kelompok orang-orang Farisi yang secara konsisten hadir sebagai "tokoh antagonis" yang berseberangan dengan Yesus. Jika dicermati dari bab 5 sampai bab 20, orangorang Yahudi ini ditampilkan sebagai lawan-lawan Yesus yang tidak akan mengubah sikap mereka pada Yesus. Karena itu, term oi 'Iovdaĩor (the Jews) dalam Injil Yohanes secara teknis merujuk kelompok tersebut. Kemungkinan besar mereka adalah orang-orang Farisi yang sangat erat memegang tradisi dan hukum Yahudi sehingga berulang kali hadir sebagai pengkritik atau penentang Yesus. ${ }^{12}$

Orang-orang ini adalah kelompok elit bangsa Yahudi dari kelompok Sanhedrin (Mahkamah Agama). Mereka adalah kelompok pemerintahan agama Yahudi yang praktis otonom: mereka boleh mengatur kehidupan Bangsa Yahudi dalam batas-batas tertentu dibawah penguasaan Roma tetapi hal menghukum mati masih dibawah kekuasaan pemerintahan Roma. ${ }^{13}$ Keanggotaannya terdiri dari 71 orang termasuk Imam Agung sebagai ketuanya.

Selain itu kelompok imam agung ini memiliki keanggotaan yang terdiri dari 3

\footnotetext{
${ }^{11}$ Steven T Katz, "Issues in the Separation of Judaism and Christianity after 70 C . E .: A Reconsideration," The Society of Biblical Literature 103, no. 1 (2018): 43-76.

${ }^{12}$ Yoel Giban, "Perbedaan Golongan Farisi, Golongan Saduki, Golongan Eseni Dan Golongan Pengikut Yesus," OSF Preprints (2021): 1-5.

${ }^{13}$ Kristoforus Bala, "Katekese Tentang Yesus Anak Allah Di Tengah Pusaran Heterdoxy: Peluang Dan Tantangannya Bagi Gereja Dewasa Ini," in Pembaharuan Gereja Melalui Katekese Superfisialisme, Aktivisme, Fundamentalisme
}

kelompok besar yakni; (1) Imam-imam kepala yakni mantan imam agung dan anggota keluarga imam agung yang merupakan calon-calon pengganti imam agung. Kelompok ini dikenal juga sebagai kaum Saduki. Dalam Injil Yohanes kelompok ini jarang ditemukan bahkan hampir-hampir tidak ada. Kelompok ini lenyap dari panggung sejarah setelah kehancuran bait Allah tahun 70 M. Sebab tempat kerja mereka ada di sekitar Bait Allah dan di sekitar altar-altar kurban.

Mereka adalah kelompok aristokrat yang memiliki banyak previlegi. Orientasi politik dan sikap orang Saduki dengan penjajah Roma berbeda dengan sikap orang Farisi yang menentang penguasa Roma. Hal ini dipengaruhi karena banyak dari antara orang Saduki adalah imam kelas atas dan tuan tanah. ${ }^{14}$

Kelompok kedua yang sangat berpengaruh dalam kehidupan orang Yahudi adalah tua-tua bangsa yakni para bangsawan-bangsawan awam yang memiliki pengaruh besar dalam masyarakat. ${ }^{15}$ Kebanyakan yang masuk dalam kelompok ini adalah orang-orang Saduki. Dan kelompok terakhir yang juga memberi pengaruh sangat besar dalam kehidupan bangsa Yahudi adalah ahli-ahli Kitab yang kebanyakan adalah kaum Farisi dan awam lainnya. Dalam Injil Yohanes

Dan Spiritualisme Tantangan Katekese Dewasa Ini, ed. Antonius Sad Budianto. Robert Pius Manik, Adi Saptowidodo (Malang: STFT Widya Sasana Malang 2018, 2018), 21-56.

${ }^{14}$ Deflit Dujerslaim Lilo, "Presuposisi Dan Metode Yesus Dalam Menyampaikan Pendapat: Sebuah Pedoman Bagi Para Akademisi," BIA': Jurnal Teologi dan Pendidikan Kristen Kontekstual 2, no. 1 (2019): 121-138.

${ }^{15}$ Giban, "Perbedaan Golongan Farisi, Golongan Saduki, Golongan Eseni Dan Golongan Pengikut Yesus." 
kelompok ini mewarnai keseluruhan kisah dan penulisan Injil Yohanes. Mereka hadir sebagai kelompok yang berseberangan dengan Yesus. Sejarah munculnya kaum Farisi dapat ditelusuri hingga zaman pemberontakan Makabe.

Pada tahun 167-164 SM terjadi pemberontakan orang-orang Yudea melawan Antiokhus Epifanes yakni penguasa Palestina pada waktu itu. Antiokhus Epifanes melakukan hal-hal yang menyakiti orang-orang Yahudi dengan mengambil barang-barang berharga dari Bait Allah di Yerusalem (1 Mak. 1:2024) dan melarang orang-orang Yahudi menempati hukum Sabat dan Sunat. Karena itu orang Yahudi melakukan pemberontakan dibawah pimpinan Matatias.

Perang ini membawa kemerdekaan bagi bangsa Yahudi dari 142 sampai $63 \mathrm{M}$. Matatias berasal dari dinasti Hasmonea atau yang dikenal sebagai keluarga Makabe. Keberhasilan perang ini juga tidak lain berkat dukungan dari kaum khasidim (kaum saleh). ${ }^{16}$ Kaum khasidim inilah yang dimaksud dalam 1 Mak. 2:42 sebagai kaum Mursyid yang gagah perkasa dan siap sedia membela Taurat.

Setelah dinasti Hasmonea berakhir, keturunan Matatias pelan-pelan mengabaikan kaum khasidim dan lebih berpihak pada imam kelas atas dan pemukapemuka Yahudi yang lebih terbuka terhadap kebudayaan Yunani. Suatu keberpihakan yang sangat ditentang dan ditolak oleh kaum khasidim. Kekecewaan

\footnotetext{
${ }^{16}$ Hendricus Pidyarto, Eksegese Kitab Suci

Perjanjian Baru Sinoptik (Malang, 2002).

${ }^{17}$ Berkhof, Sejarah Gereja.

${ }^{18}$ Pidyarto, Eksegese Kitab Suci Perjanjian Baru Sinoptik.
}

ini kemudian membuat mereka memisahkan diri menjadi satu golongan dan menyebut diri perucschim (memisahkan diri). ${ }^{17}$ Kelompok ini memisahkan diri dari orang-orang Yahudi lain yang mereka anggap tidak setia dengan Yahudi sejati. Mereka sangat memperhatikan kesucian kultis. Peraturan kesucian yang berlaku untuk para imam dan kaum Lewi dikenakan pada semua anggota kelompoknya, juga hal-hal yang menyangkut hidup sehari-hari.

Kelompok Farisi menyebut orangorang Yahudi yang lain yang tidak termasuk kelompok mereka sebagai am ha arets (rakyat tanah itu) suatu julukan yang bernada negatif. ${ }^{18}$ Artinya orang Yahudi yang termasuk am ha arets dianggap tidak mengenal Tuhan sebab mereka tidak takut berbuat dosa. Golongan Farisi menerima tradisi tertulis yakni Kitab Taurat Musa dan Kitab Para Nabi serta tradisi lisan yang dianggapnya jauh lebih luas dari tradisi tertulis. ${ }^{19}$

Tidak hanya itu kaum Farisi menaruh antipati terhadap unsur-unsur asing sebab mereka ingin mempertahankan kemurnian agama Yahudi. Sikap mereka terhadap penjajah Roma mendua, di satu sisi mereka sangat membenci penjajah Roma namun di sisi lain enggan untuk memberontak. ${ }^{20}$ Pengaruh mereka sangat kuat setelah kehancuran Bait Allah di Yerusalem. Kelompok ini memainkan peran sangat penting untuk mempertegas identitas Yahudi.

Hal ini nampak jelas dalam Yohanes pasal 9 di mana orang tua si buta

\footnotetext{
${ }^{19}$ Linwood Urban, Sejarah Ringkas Pemikiran Kristen (Jakarta: BPK Gunung Mulia, 2003).

${ }^{20}$ Runesi, "Kritik Yesus Terhadap Orang Farisi Berdasarkan Matius 23:1-12 (Sebuah Studi Eksegesis)."
} 
mengalami ketakutan yang luar biasa ketika orang Farisi mempertanyakan identitas Yesus yang menyembuhkan mata anaknya. Tentu bukan sesuatu persoalan yang biasa apabila orang tua tidak berani membela anaknya. ${ }^{21}$ Dengan kata lain ada sebuah situasi sosial yang serius di mana terjadi pengusiran yang nyata dari pemuka agama Yahudi. Dalam konteks inilah Yohanes menulis injilnya yakni ketika umat kristiani berada dibawah tekanan dari komunitas Yahudi, khususnya orang-orang Farisi yang senantiasa menghantui imannya.

Frekuensi konflik antara Yesus dengan kelompok Farisi dalam Injil Yohanes jauh lebih kompleks sebagaimana yang dinarasikan oleh Yohanes.22 Kelompok Farisi digambarkan sebagai tokoh antagonis yang secara konsisten hadir sebagai yang berseberangan dengan Yesus sampai akhir.

Kaum Farisi memang lebih populer di kalangan rakyat Yahudi sebagai pemimpin rohani bangsa. Namun banyak orang Farisi jatuh ke dalam legalisme yang terlalu mementingkan hukum-hukum yang lahiriah sampai hal-hal terkecil sehingga melupakan jiwa hukum itu sendiri. Misalnya mereka menentukan apakah orang boleh makan buah yang kebetulan jatuh dari pohon pada hari Sabat, apakah orang yang sakit gigi boleh berkumur pada hari Sabat dan lain-lain. ${ }^{23}$

\footnotetext{
${ }^{21}$ Vincent Kalvin Wenno, "Memahami Penyembuhan Orang Buta Dalam Yohanes 9 : 1-40 Dengan Pendekatan Poskolonial,"

Kurios :jurnal Teoloi dan Pendidikan Agama 5, no. 2 (2019): 166-174.

${ }^{22}$ Sanda, "Penderitaan, Dosa, Dan Pekerjaan-

Pekerjaan Allah: Eksegesis Injil Yohanes 9:2-4."

23 Ibid.

${ }^{24}$ Osvaldo Herri Bangun, "Injil Yohanes Dalam Masalah Teodise: Sebuah Upaya Menanggapai
}

Meski demikian, tidak semua pemimpin Yahudi menolak Yesus, masih ada pemimpin Yahudi yang percaya kepada Yesus seperti Nikodemus (Yoh.13). Nikodemus adalah sosok pemimpin Yahudi, seorang Farisi yang melihat mujizat-mujizat yang dikerjakan Yesus dan berkesimpulan bahwa Yesus adalah Guru yang diutus Allah. Dengan kata lain, tidak semua pemimpin Yahudi dikategorikan

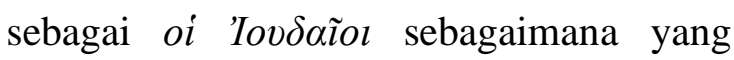
dimaksud dalam keseluruhan Injil Yohanes. $^{24}$

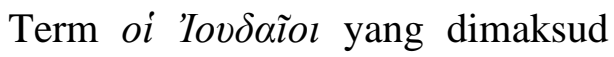
dalam Injil Yohanes karenanya hanya merujuk pada pemimpin Yahudi dan orangorang Farisi yang menolak untuk percaya kepada Yesus sejak awal sampai akhir. Dalam Yoh.12 ditemukan banyak diantara para pemimpin Yahudi yang percaya kepada Yesus tetapi sembunyi-sembunyi, sebab mereka telah sepakat siapa yang mengakui Yesus sebagai Mesias akan dikucilkan. ${ }^{25}$

\section{Pokok-Pokok Perdebatan Yesus Dengan Orang-Orang Farisi Dalam Yohanes 5:19-47}

\section{Hari Sabat}

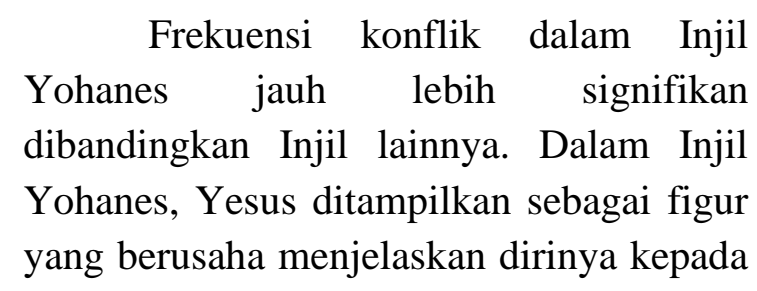

Masalah Penderitaan Berdasarkan Teks

Yohanes 9:1-7" (Universitas Kristen Duta Wacana, 2014).

${ }^{25}$ Robbyanto Notomiharjo, "Implikasi Misiologis Mujizat Penyembuhan Dalam Yohanes 9 Dan Relasinya Dengan Pelayanan Signs and Wonders Dalam Gerakan Pertumbuhan Gereja," Veritas : Jurnal Teologi dan Pelayanan 5, no. 1 (2004): 37-52. 
pemimpin Yahudi yang sejak awal menolak-Nya. ${ }^{26}$ Penolakan ini dimulai dalam pasal 5:1-18, ketika Yesus menyembuhkan seorang lumpuh di kolam Betesda pada hari Sabat. Yesus menyuruh orang lumpuh tersebut berdiri dan mengangkat tilamnya. Apa yang dibuat Yesus diamati-diamati, dilihat oleh pemimpin Yahudi. Atas dasar ini para pemimpin Yahudi melancarkan tuduhan bahwa Yesus sudah melanggar hari Sabat karena menyuruh orang lumpuh tersebut mengangkat tilam. Dengan kata lain, Yesus melawan hari Sabat, karena pada hari Sabat orang tidak boleh memikul beban berat.

Kedua, Yesus menyembuhkan orang lumpuh. Menurut orang Farisi dalam hukum Taurat pada hari sabat orang tidak boleh bekerja termasuk menyembuhkan. Padahal dalam sejarahnya, hari Sabat dimaksudkan untuk membebaskan manusia dari perbudakan kerja. Teks-teks Perjanjian Lama yang berasal dari zaman kuno belum menghubungkan hari Sabat dengan ibadah kepada Allah dan dengan hari Tuhan, melainkan hanya melarang orang mencari nafkah dan melakukan pekerjaan-pekerjaan lainnya (U1 5:15; bdk Kel 23:12).

Masih banyak peraturan lain dari orang Farisi yang bertentangan dengan isi hukum Taurat. Yesus dalam Mrk. 7:11-13 memberi satu contoh bagaimana mereka membatalkan penghormatan kepada orang tua yang jelas merupakan perintah Allah dengan dalih bahwa apa yang seharusnya dipakai untuk menyediakan kurban bagi Allah. Orang-orang Farisi juga terkenal suka membebankan kewajiban-kewajiban ke atas pundak rakyat, "tetapi mereka

\footnotetext{
${ }^{26}$ Kantohe, "Orang-Orang Farisi Dan Narsisisme Beragama: Tinjauan Mengenai Potret OrangOrang Farisi Dalam Yohanes 9."
}

sendiri tidak mau menyentuhnya" (Mat. 23:4).

Karena itu, melalui kisah penyembuhan orang sakit tersebut, Yesus tidak sedang membatalkan Sabat tetapi meluruskan makna hari Sabat. Sabat memang dihubungkan dengan ibadat kepada Allah dan dalam Im. 23:3 lalu dihubungkan dengan pertemuan kudus. Dengan demikian Sabat menjadi hari kudus untuk Tuhan (bdk. Yes 66:23; Yeh 46:1). Tetapi Sabat tidak melarang orang untuk melakukan perbuatan baik apalagi untuk menyelamatkan nyawa orang. Melainkan sebaliknya, hari Sabat adalah hari ibadah, hari Tuhan, hari penuh sukacita sebab Tuhan datang melawat umat-Nya (bdk. Hos 2:10; Yes 56:6-7). Maka segala hal baik mesti diwujudkan pada hari Sabat. Dengan demikian, penyembuhan orang lumpuh di kolam Bestesda adalah juga sarana pemberitaan sukacita Kerajaan Allah.

Oleh karena itu Yesus bersaksi tentang diri-Nya sendiri, sesungguhnya Anak tidak dapat mengerjakan sesuatu dari diri-Nya sendiri jikalau tidak melihat Bapa melakukannya sebab apa yang dikerjakan Bapa, itu juga yang dikerjakan Anak (bdk. Yoh. 5: 19-20). Pekerjaan-pekerjaan Bapa tidak lain adalah menyembuhkan orang sakit, memelihara ciptaan dan membangkitkan orang mati. ${ }^{27}$ Oleh karena itu, Sabat dapat dibatalkan bila ada kebutuhan lain yang lebih tinggi nilainya seperti adanya bahaya maut (Yoh. 7:22).

Dalam arti inilah Yesus menganggap diri tuan atas hari Sabat (Mat 12:8). Yesus melihat bahwa ada hukumhukum lebih tinggi yang mengizinkan Dia

\footnotetext{
${ }^{27}$ Sanda, "Penderitaan, Dosa, Dan PekerjaanPekerjaan Allah: Eksegesis Injil Yohanes 9:2-4.”
} 
untuk tidak menjalankan perintah Sabat, seperti perlunya menyembuhkan manusia (bdk. Mat. 12:10; Yoh. 5:10, 7:23). Hanya saja pada zaman Perjanjian Baru peraturanperaturan yang menyangkut hari Sabat menjadi begitu rumit dan menjadi salah satu kesibukan para ahli Taurat sehingga cirinya yang hakiki menjadi kabur.

Otoritas Pekerjaan dan Identitas Yesus Sebagai Putra Allah

Dalam melaksanakan misinya Yesus selalu menyadari diri-Nya sebagai utusan Bapa. Ia datang ke dunia ini bukan atas kehendak sendiri tetapi atas perutusan Bapa (Yoh. 5: 23, 37). Tujuannya untuk menyatakan Bapa, termasuk Bapa yang senantiasa bekerja memberikan keselamatan bagi seluruh ciptaan-Nya. Keselamatan dan pemeliharaan itu terus berlangsung termasuk pada hari Sabat. Dalam pemahaman Yesus, Allah tidak pernah berhenti bekerja. Kisah Allah beristirahat pada hari ketujuh tidak hendak mengatakan bahwa Allah tidak bekerja tetapi Allah berhenti menciptakan sesuatu yang baru, sebab jika Allah tidak bekerja pada hari Sabat lalu siapa yang menjamin seluruh ciptaan. ${ }^{28}$ Maka dalam pemahaman Yesus pada hari Sabat pun Bapa tetap bekerja, maka sebagai anak Ia juga bekerja (Yoh. 5:20). Perspektif inilah yang dipakai Yesus sehingga Ia menyembuhkan pada hari Sabat.

Rupanya kesaksian Yesus tentang diri-Nya tidak menyelesaikan persoalan melainkan justru menambah persoalan baru. Orang-orang Yahudi yang mendengar

\footnotetext{
${ }^{28}$ Finki Rianto Kantohe and Samuel Benjamin Hakh, "Yesus Sang Mediator Yang Merengkuh Umat Termarginalisasi: Sebuah Analisis SosioHistoris Terhadap Yohanes 9," GEMA TEOLOGIKA: Jurnal Teologi Kontekstual dan Filsafat Keilahian 5, no. 2 (2020): 207.
}

hal itu lebih berusaha lagi untuk membunuh-Nya sebab Yesus bukan saja meniadakan hari Sabat, tetapi juga karena Ia mengatakan bahwa Allah adalah Bapa-Nya sendiri dan dengan demikian menyamakan diri-Nya dengan Allah (Yoh. 5:18).

Di samping itu dalam perikop sebelumnya Sabda Yesus seringkali tidak dipahami oleh para pendengarnya. Yesus mengatakan bahwa Dia memiliki makanan yang tidak dikenali oleh orang lain termasuk murid-murid-Nya. Hal ini dikisahkan dalam Yohanes 4 ketika Yesus bercakap-cakap dengan wanita Samaria di pinggir Sumur Yakub. Ketika para murid mengajak Yesus makan, Ia mengatakan makanan Ku ialah melaksanakan kehendak Bapa (Yoh. 4: 31-34). Jadi makanan Yesus adalah melaksanakan kehendak Bapa yang mengutus-Nya.

Penegasan ini menyatakan kalau Yesus melakukan suatu pekerjaan, pekerjaan Bapalah yang dikerjakan-Nya. Dalam konteks pemikiran seperti ini dapat dipahami bahwa tujuan Yesus menyembuhkan orang lumpuh di kolam Betesda demi melakukan kehendak Bapa. Tetapi sekali lagi orang-orang Yahudi tidak percaya kepada-Nya. ${ }^{29}$ Pernyataanpernyataan Yesus justru memunculkan perdebatan semakin lama semakin sengit.

Gaya pencerita seperti ini menjadi suatu yang lazim ditemukan sebagai motif sastra dalam Injil Yohanes. Apa yang dikatakan Yesus tidak diketahui dan tidak dipahami oleh pendengarnya. Bahkan justru memunculkan konflik yang semakin besar.

\footnotetext{
${ }^{29}$ Nurnilam Sarumaha, "Pengudusan Progresif Orang Percaya Menurut 1 Yohanes 1:9," Kurios: Jurnal Teologi dan Pendidikan Agama Kristen 5, no. 1 (2019): 1-11, http://www.sttpb.ac.id/ejournal/index.php/kurios.
} 
Warta Kerajaan Allah yang diwartakan oleh Yesus memang berbeda dengan pemahaman orang Yahudi pada umumnya. Yesus mewartakan Kerajaan Allah bukan secara fisik tetapi dalam dunia rohani yang dapat dialami oleh semua orang yang percaya di mana keadilan, kedamaian, pengampunan dosa dan penyembuhan ilahi terwujud. Sedangkan dalam pemahaman orang Yahudi Kerajaan Allah bersifat teokratis saat Allah hadir sebagai hakim yang akan mengadili seluruh umat manusia, (Yesaya 4; 2-4; Yeremia 29: 10; Yeremia 23; 5-8; Yehezkiel 20: 34-38). ${ }^{30}$

Konflik dengan para pemimpin Yahudi menjadi semakin panas karena Yesus menyebut Allah sebagai Bapa (Yoh. 5:17, 18, 19-47). Memang ini sesuatu yang khas bagi orang Israel yang mengakui Allah sebagai Bapa. Tetapi jarang sekali orang Israel menyebut Allah sebagai Bapaku. Sementara Yesus menyebut Allah sebagai Bapa-Nya. Dalam pemahaman orang Yahudi pengakuan seperti itu berarti 'menduakan Allah" atau menganggap Allah memiliki anak secara harafiah. ${ }^{31}$ Maka Yesus dituduh sebagai penghujat Allah.

Dengan demikian alasan orangorang Yahudi melawan Yesus bukan hanya karena Dia melawan aturan Sabat tetapi juga karena Yesus menyebut Allah sebagai Bapanya (Yoh. 5:18). Karena dengan demikian, Ia menyamakan diri-Nya dengan Allah. Maka, orang Yahudi lebih berusaha lagi untuk membunuh Dia. ${ }^{32}$ Inilah motifmotif tuduhan orang-orang Yahudi

\footnotetext{
${ }^{30}$ Santosa, "Konsep Kerajaan Allah Menurut Yesus."

${ }^{31}$ Heri Susanto, "Yesus Sebagai Anak Allah Menurut Injil Matius Dan Implementasinya Dalam Berapologetika," Logia 1, no. 1 (2020): 78-95.
}

terhadap Yesus yang sudah muncul di bab 5 dan terus-menerus di bawah sampai akhir.

Ketika Yesus dihadapkan kepada Pilatus, orang-orang Yahudi melancarkan tuduhannya sama, Dia sudah menghujat Allah. Dari sini dapat disimpulkan bahwa salib yang menjadi puncak narasi dalam Injil Yohanes sudah dipersiapkan sejak pasal 5 dalam konflik antara Yesus dan orang-orang Yahudi. Kedua tuduhan ini menjadi tuduhan yang terus-menerus dibawa oleh orang-orang Yahudi untuk menjerat Yesus. Di satu pihak Yesus meniadakan hukum Sabat dan kedua menyamakan dirinya dengan Allah.

\section{Kesaksian Yesus Tentang Diri-Nya Sendiri} Setelah Yesus menyembuhkan orang lumpuh di kolam Betesda, orangorang Yahudi lebih berusaha lagi untuk membunuh-Nya. Ancaman ini menjadi kesempatan bagi Yesus untuk menjelaskan dan mewahyukan diri-Nya. Yesus memberi kesaksian sesungguhnya Anak tidak dapat mengerjakan sesuatu dari dirinya sendiri kalau tidak melihat Bapa mengerjakan (Yoh 5:19). Singkat kata, Yesus melakukan apa yang dikerjakan Bapa dan itu yang disebut makanan-Nya.

Yesus selalu menyadari Dia adalah utusan Bapa. Seorang utusan tentu tidak memiliki otoritas apa-apa dari dirinya sendiri. Otoritas dan kuasa pengajaran seorang utusan berasal dari Dia yang mengutus-Nya (Yoh. 5:24). Maka tugas Yesus adalah menyelesaikan pekerjaan Bapa. Pekerjaan Bapa itu tidak lain

\footnotetext{
${ }^{32}$ Manafe, "STTE Konsep Kesatuan Yesus Dan Allah Bapa Dalam Injil Yohanes 17 : 22 Untuk Menghadapi Doktrin Subordinansi Tritunggal Saksi Yehuwa."
} 
membangkitkan orang mati, menyembuhkan dan menghakimi baik di dunia ini maupun di dunia akhirat.

Dengan membangkitkan orang mati, Yesus memberi kehidupan baru. Sebab tujuan inkarnasinya sebagai Anak Tunggal Bapa (Mat. 1:18-23; Luk. 2:6-7) untuk menyelamatkan umat manusia dari dosa (Mat. 1:21), dengan cara demikian menjadi tebusan bagi banyak orang (Mrk. 10:45).

Semua hal ini diwujudkan oleh Yesus melalui kehidupan, pelayanan, penderitaan, dan kematian-Nya agar manusia diselamatkan dari kematian kekal. ${ }^{33}$ Kebenaran-kebenaran inilah yang menjadi inti pewahyuan dan kesaksian Yesus tentang diri-Nya dalam Yohanes 5:19-47 agar semua orang percaya dan diselamatkan (Yoh. 5:34). Karena itu, Ia berkata, "Pekerjaan yang $\mathrm{Ku}$ kerjakan sekarang itulah yang memberi kesaksian tentang Aku, bahwa Bapalah yang mengutus Aku" (Yoh. 5:36). Sebab sama seperti Bapa membangkitkan orang-orang mati dan menghidupkannya demikian juga Anak menghidupkan barang siapa yang dikehendaki-Nya (Yoh. 5:21). Kalau Yesus menghakimi, Dia tidak menghakimi dengan kuasanya sendiri tetapi dengan kuasa yang diberikan Bapa kepada-Nya.

Yesus juga diberi wewenang oleh Allah untuk memberi hidup kekal dan hidup kekal ini diberikan kepada orang-orang yang percaya kepada-Nya (Yoh. 5: 28-29). Jadi iman dan kepercayaan kepada Yesuslah yang menyelamatkan seseorang karena meskipun seseorang menyelidiki Kitab Suci kalau tidak datang kepada-Nya

\footnotetext{
${ }^{33}$ Peniel C. D. Maiaweng, "Inkarnasi: Realita Kemanusiaan Yesus,” Jurnal Jaffray: Sekolah Tinggi Theologia Jaffray 13, no. 1 (2015): 97-
}

maka tidak memperoleh hidup kekal (Yoh 5:39-40). Karena segala sesuatu yang dituliskan Musa dalam Taurat semuanya tentang Diri-Nya (Yoh.5: 46). Dengan kata lain, tujuan utama kedatangan Yesus untuk mewahyukan Allah kepada dunia, supaya dunia mengenal Allah, karena dengan mengenal Allah dunia memperoleh keselamatan.

Ketika Yesus bersaksi tentang pekerjaan dan diri-Nya sendiri muncullah begitu banyak tuduhan bahwa bersaksi tentang diri-Nya sendiri (Yoh. 5:30). Dalam tata hukum Yahudi, kesaksian tentang dirinya sendiri tidak dapat diterima. Maka ketika Yesus memberikan kesaksian tentang dirinya sendiri, orang Yahudi mengatakan kesaksiannya ini tidak sah.

Atas tuduhan ini Yesus membantah kalau Dia bersaksi tentang dirinya maka kesaksiannya tidak benar. Sebab ada pihak lain yang memberi kesaksian tentang dirinya yakni, Yohanes pembaptis, pekerjaan-pekerjaan-Nya dan Kitab Suci memberi kesaksian tentang diri-Nya (Yoh. 5: 36-37). Yohanes pembaptis sudah memberi kesaksian tentang Yesus sehingga banyak orang termasuk muridnya datang mengikuti Yesus, maka kesaksian yang diberikan Yohanes itu adalah kesaksian yang kuat, karena menarik banyak orang untuk mengikuti-Nya.

Di samping itu pekerjaan, mujizat dan pengajaran Yesus yang penuh wibawa membuktikan kalau Yesus datang dari Allah. Sebab Kitab Suci juga memberi kesaksian bahwa janji sang Mesias harus digenapi (Yoh. 5: 39). Tetapi sekali lagi orang Yahudi tetap tidak menaruh

120 , https://ojs.sttjaffray.ac.id/JJV71/article/view/114/ pdf_80. 
kepercayaan kepada Yesus. Hal ini membuktikan bahwa di dalam hati pemimpin-pemimpin Yahudi sudah tidak lagi mempunyai kasih akan Allah (Yoh. 5:42). Tanda memiliki kasih akan Allah apabila seseorang mendengar kesaksian Yohanes, menyelidiki Kitab Suci dan Taurat Musa serta percaya kepada pekerjaan-pekerjaan Yesus maka Firman Allah akan menetap dalam dirinya sehingga dia percaya kepada Allah yang mengutus Yesus (Yoh. 5:38).

Sejak saat itu orang-orang Yahudi tidak menaruh kepercayaan kepada Yesus. Apa saja yang dikatakan Yesus menimbulkan perlawanan bahkan mereka lebih berusaha lagi membunuh Dia (Yoh. 7:1). Dengan kata lain, Yohanes segaja menempatkan pada bagian awal Injil alasan-alasan penyaliban Yesus. Yohanes merumuskan hal tersebut dalam bingkai perdebatan Yesus dengan para pemimpinpimpin Yahudi yang sejak awal tidak menaruh perhatian kepada Yesus. Karena itu, sepanjang injilnya Yohanes menampilkan Yesus yang berusaha meyakinkan orang Yahudi tentang kuasa dan otoritas perkataan dan pengajarannya. Misalnya tentang ajaran hidup kekal, roti hidup (6:25-59), air hidup (Yoh 7:37-44), gembala yang baik (Yoh. 10: 1-21). Namun mereka tetap bersikeras untuk menolak dan tidak percaya.

Melalui metode bercerita semacam ini, Injil Yohanes ingin mengajak para pembacanya bahwa untuk memperoleh hidup kekal pertama-tama harus menaruh kepercayaan kepada Yesus. Iman kepada Yesus adalah pintu masuk untuk memperoleh hidup yang kekal (Yoh. 5:24) dan diselamatkan (Yoh. 5:34). Sebab dengan iman akan Yesus Kristus orang akan mengerti Kitab Suci dan pekerjaanpekerjaan yang dikerjakan Yesus (Yoh. 5: 45-47).

Jadi implikasi perikop Injil Yohanes 5: 19-47 bagi umat kristiani saat ini ialah bahwa iman dan penyerahan diri yang total kepada Yesus adalah sarana untuk memahami misteri keselamatan Allah yang telah nyata dalam perkataan, pengajaran dan pekerjaan-pekerjaan Yesus.

\section{KESIMPULAN}

Injil Yohanes ditulis ketika orang kristiani hidup dalam tekanan yang berat baik dari penjajah Roma maupun dari pemimpin-pemimpin Yahudi yang menjaga kemurnian agama Yahudi. Oleh karena itu ciri literer Injil Yohanes banyak menampilkan pengajaran dan Sabda-Sabda Yesus dan kurang banyak menampilkan kisah dan karya-karya Mujizat Yesus. Pada umumnya Injil Yohanes berisi pembelaan dan kesaksian Yesus mengenai identitas dan otoritas pekerjaan-Nya. Teks-teks ini merupakan bentuk tanggapan terhadap orang-rang Farisi yang menentang Yesus sejak awal hingga akhir. Karena itu dapatlah dimengerti mengapa Injil Yohanes memiliki makna teologis yang dalam dan kaya akan simbol-simbol teologi.

Tujuan teologis di balik penulisan Injil ini tidak lain adalah untuk menguatkan iman umat yang sedang berada dalam tekanan yang hebat dari orang-orang Yahudi dan semua orang bertobat dan percaya kepada Kristus sebagai Mesias yang dijanjikan. Sebab keselamatan pertama-tama menyangkut iman yang dibuktikan dengan menerima pekerjaanpekerjaan dan Sabda Yesus.

Dengan demikian Injil Yohanes ditulis bukan pertama-tama untuk 
memaparkan fakta historis tentang Yesus melainkan agar semua orang percaya bahwa Yesus adalah Kristus Putera Allah yang hidup. Dan dalam dan melalui Dialah semua bangsa diselamatkan.

Bagi umat kristiani yang saat ini sedang menghadapi badai pandemi Covid19, pengalaman jemaat yohanian mengajarkan kita bahwa di tengah beratnya terpaan pandemi Covid-19 Allah tidak pernah meninggalkan umat-Nya. Allah berjuang bahkan menderita bersama umatNya. Kehadiran dan keterlibatan Allah dapat dirasakan lewat solidaritas dan kesetiaan sesama yang senantiasa hadir dan menolong. Tetapi sentuhan kasih Allah ini hanya dapat dirasakan jika kita memiliki iman dan kepercayaan yang teguh kepada Yesus Sang penyelamat dunia.

\section{REFFERENSI}

Bala, Kristoforus. "Katekese Tentang Yesus Anak Allah Di Tengah Pusaran Heterdoxy: Peluang Dan

Tantangannya Bagi Gereja Dewasa Ini." In Pembaharuan Gereja Melalui Katekese Superfisialisme, Aktivisme, Fundamentalisme Dan Spiritualisme Tantangan Katekese Dewasa Ini, edited by Antonius Sad Budianto. Robert Pius Manik, Adi Saptowidodo, 21-56. Malang: STFT Widya Sasana Malang 2018, 2018.

Bangun, Osvaldo Herri. "Injil Yohanes Dalam Masalah Teodise: Sebuah Upaya Menanggapai Masalah Penderitaan Berdasarkan Teks Yohanes 9:1-7." Universitas Kristen Duta Wacana, 2014.

Berkhof, Hendrikus. Sejarah Gereja. Edited by H. Enklaar. 24th ed. Jakarta: BPK Gunung Mulia, 2009. Giban, Yoel. "Perbedaan Golongan Farisi, Golongan Saduki, Golongan Eseni Dan Golongan Pengikut Yesus." OSF
Preprints (2021): 1-5.

Jonch, Christian. "Yesus Sebagai Guru : Studi Injil Yohanes." Veritas : Jurnal Teologi dan Pelayanan 8, no. 2 (2007): 257-276.

Kantohe, Finki Rianto. "Orang-Orang Farisi Dan Narsisisme Beragama: Tinjauan Mengenai Potret OrangOrang Farisi Dalam Yohanes 9." Jurnal Abdiel: Khazanah Pemikiran Teologi, Pendidikan Agama Kristen dan Musik Gereja 4, no. 2 (2020): 180-198.

Kantohe, Finki Rianto, and Samuel Benjamin Hakh. "Yesus Sang Mediator Yang Merengkuh Umat Termarginalisasi: Sebuah Analisis Sosio-Historis Terhadap Yohanes 9." GEMA TEOLOGIKA: Jurnal Teologi Kontekstual dan Filsafat Keilahian 5, no. 2 (2020): 207.

Katz, Steven T. "Issues in the Separation of Judaism and Christianity after $70 \mathrm{C}$ . E .: A Reconsideration." The Society of Biblical Literature 103, no. 1 (2018): 43-76.

Lakonawa, Petrus. "Memaknai SimbolSimbol Religius Injil Yohanes." Humaniora 5, no. 1 (2014): 324.

Lilo, Deflit Dujerslaim. "Presuposisi Dan Metode Yesus Dalam Menyampaikan Pendapat: Sebuah Pedoman Bagi Para Akademisi." BIA': Jurnal Teologi dan Pendidikan Kristen Kontekstual 2, no. 1 (2019): 121-138.

Maiaweng, Peniel C. D. "Inkarnasi: Realita Kemanusiaan Yesus.” Jurnal Jaffray: Sekolah Tinggi Theologia Jaffray 13, no. 1 (2015): 97-120.

https://ojs.sttjaffray.ac.id/JJV71/articl e/view/114/pdf_80.

Manafe, Yanjumseby Y. "STTE Konsep Kesatuan Yesus Dan Allah Bapa Dalam Injil Yohanes 17 : 22 Untuk Menghadapi Doktrin Subordinansi Tritunggal Saksi Yehuwa.” Jurnal Scripta Teologi dan Pelayanan Kontekstual 4, no. 1 (2019): 1-14. 
Notomiharjo, Robbyanto. "Implikasi

Misiologis Mujizat Penyembuhan

Dalam Yohanes 9 Dan Relasinya

Dengan Pelayanan Signs and

Wonders Dalam Gerakan

Pertumbuhan Gereja." Veritas :

Jurnal Teologi dan Pelayanan 5, no. 1 (2004): 37-52.

Pidyarto, Hendricus. Eksegese Kitab Suci

Perjanjian Baru Sinoptik. Malang, 2002.

Runesi, Epelina Yofita. "Kritik Yesus

Terhadap Orang Farisi Berdasarkan

Matius 23:1-12 (Sebuah Studi

Eksegesis)." Repository Sekolah

Tinggi Teologi Injili Arastamar

(SETIA) Jakarta 12 (2015).

Sanda, Hendrik Yufengkri. "Penderitaan, Dosa, Dan Pekerjaan-Pekerjaan

Allah: Eksegesis Injil Yohanes 9:2-

4." KAMASEAN: Jurnal Teologi

Kristen 1, no. 1 (2020): 35-54.

Santosa, Nur Budi. "Konsep Kerajaan

Allah Menurut Yesus." Jurnal

Antusias (2013).

Sarumaha, Nurnilam. "Pengudusan
Progresif Orang Percaya Menurut 1

Yohanes 1:9." Kurios: Jurnal Teologi dan Pendidikan Agama Kristen 5, no. 1 (2019): 1-11. http://www.sttpb.ac.id/ejournal/index.php/kurios.

Scheunemann, Rainer. Panduan Lengkap Penafsiran Alkitab: Perjanjian Lama Dan Perjanjian Baru. Yogyakarta: ANDI Offset Yogyakarta, 2009.

Susanto, Heri. "Yesus Sebagai Anak Allah Menurut Injil Matius Dan Implementasinya Dalam Berapologetika." Logia 1, no. 1 (2020): 78-95.

Urban, Linwood. Sejarah Ringkas Pemikiran Kristen. Jakarta: BPK Gunung Mulia, 2003.

Wenno, Vincent Kalvin. "Memahami Penyembuhan Orang Buta Dalam Yohanes 9: 1-40 Dengan Pendekatan Poskolonial." Kurios :jurnal Teoloi dan Pendidikan Agama 5, no. 2 (2019): 166-174. 